\title{
Stoichiometry and surface structure dependence of hydrogen evolution reaction activity and stability of MoxC MXenes
}

Saad Intikhab, Varun Natu, Justin Li, Yawei Li, Quanzheng Tao, Johanna Rosén, Michel W. Barsoum and Joshua Snyder

The self-archived postprint version of this journal article is available at Linköping University Institutional Repository (DiVA):

http://urn.kb.se/resolve?urn=urn:nbn:se:liu:diva-157566

N.B.: When citing this work, cite the original publication.

Intikhab, S., Natu, V., Li, J., Li, Y., Tao, Q., Rosén, J., Barsoum, M. W., Snyder, J., (2019),

Stoichiometry and surface structure dependence of hydrogen evolution reaction activity and stability of MoxC MXenes, Journal of Catalysis, 371, 325-332. https://doi.org/10.1016/j.jcat.2019.01.037

Original publication available at:

https://doi.org/10.1016/j.jcat.2019.01.037

Copyright: Elsevier

http://www.elsevier.com/

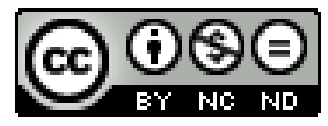




\title{
Stoichiometry and Surface Structure Dependence of HER Activity and Stability of Mox $\mathrm{C}$ Menes
}

Saad Intikhab ${ }^{1}$, Varun Natu ${ }^{2}$, Justin Li $^{2}$, Yawei Li ${ }^{1}$, Quanzheng Tao ${ }^{3}$, Johanna Rosen ${ }^{3}$, Michel W. Barsoum ${ }^{2}$, Joshua Snyder ${ }^{1, *}$

${ }^{1}$ Chemical and Biological Engineering, Drexel University, Philadelphia, Pennsylvania 19104, United States

${ }^{2}$ Materials Science and Engineering, Drexel University, Philadelphia, Pennsylvania 19104, United States

${ }^{3}$ Thin Film Physics Division, Department of Physics, Chemistry and Biology (IFM), Linköping University, SE-581 83 Linköping, Sweden

*Corresponding Author: Joshua Snyder, jds43@drexel.edu

\begin{abstract}
The exploration of non-precious catalysts for the hydrogen evolution reaction (HER) remains critical in the commercialization of electrochemical energy storage and conversion technologies. Two-dimensional transitional metal carbides called MXenes have been found to have great potential as electrocatalysts for HER. In this work, we synthesize two Mo based MXenes: $\mathrm{Mo}_{1.33} \mathrm{CT}_{\mathrm{z}}$ and $\mathrm{Mo}_{2} \mathrm{CT}_{\mathrm{z}}$ and measure their HER activity and operational durability. The ordered divacancies on the basal planes of $\mathrm{Mo}_{1.33} \mathrm{CT}_{z}$ cause a marked decrease in HER activity compared to $\mathrm{Mo}_{2} \mathrm{CT}_{\mathrm{z}}$. The stoichiometry and atomic surface structure of MXenes is found to be critically important for catalytic activity while having less of an impact on operational durability. This work provides insight for the development active 2D materials for HER and other technologically relevant electrochemical reactions.
\end{abstract}

\section{Introduction}

Advances in electrochemical energy storage and conversion are required to drive commercialization of renewable energy technologies, i.e. solar and wind, bridging the gap between peak power production and peak energy demand. Hydrogen sourced from water, with its high energy density and single intermediate electrochemical oxidation/reduction reactions, is an ideal carbon neutral electrochemical fuel, storing intermittent renewable energy in the form of chemical bonds ${ }^{1}$. The cathodic production of hydrogen gas through water electrolysis, $\mathrm{H}_{2}$-evolution reaction 
(HER), is traditionally driven with nanostructured Pt or other platinum group metals (PGM) ${ }^{2,3}$. However, commercialization of electrochemical energy storage and conversion technologies, specifically fuel cells and electrolyzers, is reliant upon the development of new electrocatalytic materials that reduce operational overpotentials and lower, or eliminate, PGM loadings. Significant effort has centered on the development of non-PGM HER electrocatalysts including sulfides $^{2,4-6}$, nitrides ${ }^{7}$, carbides $^{8,9}$, phosphides $^{10,11}$, etc., possessing a range of stoichiometries and morphologies. To this point, however, limitations associated with activity and operational durability of these materials remain ${ }^{3}$.

Molybdenum carbide is one of the most widely studied transition metal carbide based catalysts for $\mathrm{HER}^{9,12-15}$. Vrubel et al. showed that the activity of bulk $\mathrm{Mo}_{2} \mathrm{C}$ is relatively independent of $\mathrm{pH}$, with overpotentials at $10 \mathrm{~mA} / \mathrm{cm}^{2}, \eta$, at $\mathrm{pH} 0$ and 14 of $209 \mathrm{mV}$ and $191 \mathrm{mV}^{9}$, respectively. Since then, many different phases of $\mathrm{Mo}_{\mathrm{x}} \mathrm{C}$ such as $\alpha-\mathrm{Mo}_{2} \mathrm{C}, \beta-\mathrm{Mo}_{2} \mathrm{C}, \eta-\mathrm{MoC}$, and $\gamma$-MoC, among others, have been assessed for their HER activity ${ }^{9,13-15}$. Furthermore, various strategies including nano-structuring, N/S doping, etc. have also been used to further improve the performance of the $\mathrm{Mo}_{\mathrm{x}} \mathrm{C}$ catalysts ${ }^{8,13-16}$. Significant reduction in HER $\eta$ for $\mathrm{Mo}_{\mathrm{x}} \mathrm{C}$ materials has been achieved through N/S doping of either the supporting material ${ }^{15}$ or the $\mathrm{Mo}_{\mathrm{x}} \mathrm{C}$ materials themselves ${ }^{16}$. The effect of covalent interaction between the active Mo sites in the material and dopants induces a redistribution of charge, optimizing the adsorption free energy of the $\mathrm{H}$ intermediate. ${ }^{15,16}$

MXenes, an exfoliated material possessing the general formula $M_{n+1} X_{n} T_{z}(n=1-3)$ where $M$ is a transition metal, $X$ is carbon and/or nitrogen, and $T_{Z}$ represents surface functional groups including $-\mathrm{O},-\mathrm{OH}$, and $-\mathrm{F}$, are derived from the selective etching of the A-layers from MAX phases $^{17,18}$. MAX phases are ternary layered hexagonal machinable carbides and nitrides where $\mathrm{M}$ is an early transition metal, $\mathrm{A}$ is an $\mathrm{A}$ group element and $\mathrm{X}$ is either $\mathrm{C}$ and/or N. MXenes possess a broad range of properties that make them attractive materials for electrocatalysis ${ }^{8,19}$. Recent computational and experimental analysis of Mo based MXenes have demonstrated their potential as an effective HER catalyst ${ }^{8,20,21}$. DFT analysis of HER reactive intermediate adsorption on $\mathrm{M}_{2} \mathrm{CT}_{\mathrm{z}}(\mathrm{M}=$ transition metal) single layer materials predicted a near thermoneutral free energy of adsorption for $\mathrm{H}\left(\Delta G_{H_{a d}}\right)$ over a wide range of $\mathrm{H}$ surface coverages, with $\mathrm{Mo}_{2} \mathrm{CT}_{\mathrm{z}}$ sitting close to the peak of the reactivity volcano ${ }^{20}$. Seh et al. ${ }^{8}$ measured the HER activity of $\mathrm{Mo}_{2} \mathrm{CT}_{\mathrm{z}}$ experimentally and found it to be a promising HER catalyst, reporting an overpotential of $283 \mathrm{mV}$ 
at $10 \mathrm{~mA} / \mathrm{cm}^{2}$. Respectable HER activity has also been demonstrated for Mo-based 2D borides following etching of $\mathrm{Al}$ from the MoAlB MAB phase, exposing the catalytically active basal planes $^{21}$. Even though both the $\beta-\mathrm{Mo}_{2} \mathrm{C}^{16}$ nanosheets and $\mathrm{Mo}_{2} \mathrm{C} \mathrm{MXene}^{8}$ have similar nanostructures, the overpotentials $\left(320 \mathrm{mV}\right.$ and $283 \mathrm{mV}$ respectively, in $0.5 \mathrm{M} \mathrm{H}_{2} \mathrm{SO}_{4}$ ) are significantly different indicating a role of crystal structure and surface terminations on the catalyst activity. Atomic scale defects/vacancies can have significant effects on electrocatalytic activity as demonstrated for $\mathrm{Mo}_{2} \mathrm{C}$ where surfaces possessing an off-stoichiometry and $\mathrm{Mo}^{3+}$ defects are found to have enhanced HER activity ${ }^{22}$. For oxidative reactions, lower coordinated defects can promote the formation of participatory hydroxl species ${ }^{23-30}$. For reductive reactions, surface defects in the form of vacancies can potentially increase the active site density (higher population of reactive, dangling bonds), change the intrinsic conductivity of the catalyst ${ }^{31}$, or manipulate the electronic properties of the surface. All of these effects have the potential to impact catalyst activity.

Typical methodologies for introducing defects, however, lack control over the defect type, extent and density of defect distribution throughout the material, and are typically limited to macroscale defects. A new type of chemically ordered quaternary MAX phase, $i$-MAX, of the general formula $\left(M_{2 / 3}^{1} M_{1 / 3}^{2}\right)_{2} A l C^{32,33}$, evolves into a MXene, upon etching, possessing ordered divacancies present in a chain-like sinusoidal pattern ${ }^{31,32,34}$. A Mo-carbide MXene with ordered divacancies, possessing the stoichiometry $\mathrm{Mo}_{1.33} \mathrm{CT}_{\mathrm{z}}$, can be formed through the etching of $\mathrm{Al}$ and $\mathrm{Sc} / \mathrm{Y}$ from $\left(\mathrm{Mo}_{2 / 3} \mathrm{Sc}_{1 / 3}\right)_{2} \mathrm{AlC}$ or $\left(\mathrm{Mo}_{2 / 3} \mathrm{Y}_{1 / 3}\right)_{2} \mathrm{AlC}$, respectively ${ }^{31,35}$. The result is a $\mathrm{Mo}_{1.33} \mathrm{CT}_{\mathrm{z}} 2 \mathrm{D}$ MXene with ordered divacancies, imparting both an enhanced conductivity and electrochemical capacitance to the material ${ }^{31}$.

In this work, we assess and compare the stoichiometry and surface structure dependency of HER activity and operational durability for Mo based MXenes; $\mathrm{Mo}_{1.33} \mathrm{CT}_{\mathrm{z}}$ vs. $\mathrm{Mo}_{2} \mathrm{CT}_{\mathrm{z}}$. Comparison of the HER activities indicates a marked decrease in activity for the $\mathrm{Mo}_{1.33} \mathrm{CT}_{\mathrm{z}}$, containing ordered divacancies ${ }^{31,36}$, with respect to $\mathrm{Mo}_{2} \mathrm{CT}_{\mathrm{z}}$. We hypothesize that the presence of the vacancy defects on $\mathrm{Mo}_{1.33} \mathrm{CT}_{\mathrm{z}}$ basal surfaces changes the average coordination of carbon and $-\mathrm{O}$ terminated Mo sites, resulting in a detrimental effect to the adsorption of the reactive $\mathrm{H}$ intermediate. Further, the activity of both MXenes, as with other Mo carbide electrocatalysts, was found to be independent of $\mathrm{pH}$. This is in contrast to Pt, and other PGM materials, in which the 
HER activity at alkaline $\mathrm{pH}$ is found to be orders of magnitude lower ${ }^{37}$. Operational durability testing through load cycling indicates acceptable stability of both $\mathrm{Mo}_{2} \mathrm{CT}_{\mathrm{z}}$ and $\mathrm{Mo}_{1.33} \mathrm{CT}_{\mathrm{z}}$.

\section{Experimental Details}

\subsection{Mo2Ga2C Synthesis}

The $\mathrm{Mo}_{2} \mathrm{Ga}_{2} \mathrm{C}$ MAX phase, used as a precursor for making $\mathrm{Mo}_{2} \mathrm{CT}_{\mathrm{z}}$ MXene, was synthesized according to a process reported previously by Halim et al. ${ }^{38}$ Briefly, $\alpha-\mathrm{Mo}_{2} \mathrm{C},(\sim 99.5 \%$ purity, Alfa Aesar, USA) powder was mixed with gallium, Ga, metal in a 1:8 molar ratio, respectively. To ensure a homogeneous mixture, Ga shot, with a melting point close to room temperature, was added to the $\alpha-\mathrm{Mo}_{2} \mathrm{C}$ powder in a mortar and mixed thoroughly using a pestle

until a homogenous slurry was obtained. This mixture was then transferred to a quartz tube, which was evacuated using a mechanical vacuum pump. The vacuum $(\sim 90 \mathrm{kPa})$ was pulled for $1 \mathrm{~h}$ and then the tube was purged with argon, Ar. This step was repeated 3 times to ensure all residual air was displaced. Vacuum was pulled overnight, and the quartz tube was sealed off while under vacuum. The tube was then placed vertically in a box furnace and heated in air to $850^{\circ} \mathrm{C}$ at a heating rate of $5^{\circ} \mathrm{C} / \mathrm{min}$, and held at that temperature for $168 \mathrm{~h}$ and then cooled to room temperature (RT). To dissolve excess Ga, the resulting powders were removed from the tube and soaked in 12 $\mathrm{M}$ hydrochloric acid, $\mathrm{HCl}$, under $500 \mathrm{rpm}$ stirring at $\mathrm{RT}$ for $12 \mathrm{~h}$. After $\mathrm{HCl}$ treatment the powders were washed to neutral $\mathrm{pH}$ using DI water and air dried before further use.

\section{2 $\mathrm{Mo2}_{2} \mathrm{CT}_{\mathrm{z}} \mathrm{MXene}$ Synthesis}

One gram of $\mathrm{Mo}_{2} \mathrm{Ga}_{2} \mathrm{C}$ powder was slowly added to $40 \mathrm{~mL}$ of $14 \mathrm{M}$ solution of hydrofluoric acid, $\mathrm{HF}$, and stirred at $500 \mathrm{rpm}$ at $55^{\circ} \mathrm{C}$ for $168 \mathrm{~h}$. After etching, the acidic slurry was carefully added to a centrifuge tube and DI water was added to the solution which was subsequently centrifuged at $3500 \mathrm{rpm}$ for 2 mins. After centrifugation, the clear supernatant was discarded, and DI water was added again and the tube was thoroughly shaken. This process was repeated several times until the $\mathrm{pH}$ of the supernatant was $>6$. The thick slurry obtained after the last wash was added to $2 \mathrm{ml}$ of $1.5 \mathrm{M}$ tetrabutylammonium hydroxide, TBAOH, solution. The mixture was then shaken using a vortex mixer for $0.5 \mathrm{~h}$ to promote $\mathrm{TBA}^{+}$ion intercalation. Then $40 \mathrm{ml}$ of 200 proof ethanol, EtOH, was added, and the solution was further shaken for 2 mins and centrifuged at 3500 rpm for 2 mins. The EtOH supernatant was then discarded and the process was repeated 3 more 
times. The ethanol step was carried out to wash off any excess TBAOH, since it is known to be a good solvent for TBAOH. It also prevents MXene from deflocculating. After the final wash, 30 $\mathrm{ml}$ of DI water was added to the MXene slurry which was subsequently shaken for $0.5 \mathrm{~h}$ to form a $\mathrm{Mo}_{2} \mathrm{CT}_{\mathrm{z}}$ colloidal suspension. To separate the non-delaminated MXene particles, the colloidal solution was centrifuged at $3500 \mathrm{rpm}$ for $0.5 \mathrm{~h}$ and the supernatant was stored for further use. To measure the MXene concentration, a known volume of colloid suspension was vacuum filtered through a Celgard membrane. The vacuum filtered films were then peeled off and dried in vacuum at $100{ }^{\circ} \mathrm{C}$ for $12 \mathrm{~h}$ before weighing. This free standing MXene paper was used for XRD analysis.

\section{$2.3\left(\mathrm{Mo}_{2} / 3 \mathrm{Sc}_{1 / 3}\right)_{2} \mathrm{AlC}$ Synthesis}

To synthesize the ( $\left.\mathrm{Mo}_{2 / 3} \mathrm{Sc}_{1 / 3}\right)_{2} \mathrm{AlC} \mathrm{MAX}$ phase, graphite (99.999\%), Mo (99.99\% SigmaAldrich), Al (99.8\% Alfa Aesar), and Sc (99.99\% Stanford Advanced Material) powders were mixed in an agate mortar in the $\left(\mathrm{Mo}_{2 / 3} \mathrm{Sc}_{1 / 3}\right)_{2} \mathrm{AlC}$ stoichiometric ratio and heated to $1500^{\circ} \mathrm{C}$ in an alumina crucible under flowing Ar for $20 \mathrm{~h}$. After cooling down to RT in the furnace, a loosely packed powder was obtained. The powder was crushed and passed through a 200 mesh sieve (particle size $<74 \mu \mathrm{m}$ ).

\subsection{Mo1.33CT $\mathrm{z}$ Mene Synthesis}

One gram of $\left(\mathrm{Mo}_{2 / 3} \mathrm{Sc}_{1 / 3}\right)_{2} \mathrm{AlC}$ powder was added to $20 \mathrm{~mL}$ of $28 \mathrm{M}$ HF solution and stirred at RT and $500 \mathrm{rpm}$ for $24 \mathrm{~h}$. After etching, the washing and delamination procedures were similar to those described above for $\mathrm{Mo}_{2} \mathrm{CT}_{\mathrm{z}}$. Briefly, the etched $\mathrm{Mo}_{1.33} \mathrm{CT}_{\mathrm{z}}$ powders were washed with DI water until the $\mathrm{pH}$ of the supernatant was $\sim 7$. This was followed by $\mathrm{TBA}^{+}$ion intercalation. The excess $\mathrm{TBAOH}$ was removed with $\mathrm{EtOH}$ followed by formation of a colloidal suspension with DI water. The colloidal suspension was centrifuged at $3500 \mathrm{rpm}$ for $0.5 \mathrm{~h}$ to separate out any non-delaminated particles.

\subsection{Electrochemical Measurements}

The electrochemical experiments were conducted in a three electrode FEP electrochemical cell with an Autolab (PGSTAT302N) potentiostat. HER activity was measured using a rotating disk electrode (RDE) setup at a rotation rate of $1600 \mathrm{rpm}$. MXenes were used to prepare catalytic inks by diluting with ultrapure DI water. A known volume of ink was drop-cast onto a glassy carbon (GC) disk (5 mm diameter) and dried under Ar (Research grade, Airgas) flow. The disk 
was mounted in a hanging meniscus holder and transferred into the electrochemical cell with $\mathrm{H}_{2}$ purged electrolyte under potential control. The electrolytes were prepared with high purity $\mathrm{HClO}_{4}$ (70 wt\%, Suprapur, Merck) or KOH pellets (99.99\% [metal basis], Sigma) and 18.2 M $\Omega$ cm Milli$\mathrm{Q}$ water. GDL carbon paper was used as the counter electrode and a $\mathrm{Ag} / \mathrm{AgCl}$ reference (BASi) electrode was used for all measurements. All potentials, reported in the manuscript, have been converted to the reversible hydrogen electrode (RHE) scale. All voltages were corrected for iR drop.

\subsection{Material Characterization}

A VersaProbe 5000 spectrometer (Physical Electronics, Chanhassen, Minnesota, USA) was used for X-ray photoelectron spectroscopy (XPS) surface analysis. The glassy carbon disks unto which the MXene was drop cast, were directly mounted on the sample holder in the XPS. A pass energy of $23.5 \mathrm{eV}$ was used for all scans. The step size and step times were set to $0.050 \mathrm{eV}$ and $100 \mathrm{~ms}$, respectively. No $\mathrm{Ar}^{+}$sputtering was used during this analysis. The number of repeat scans was set to 25. CasaXPS Version 2.3.19PR1.0 software was used for peak fitting using the similar procedure outlined in Refs. ${ }^{31,38}$. The XPS spectra was calibrated by setting the valence edge to zero. Because MXenes are conductive, asymmetric peaks were used to fit the Mo-C regions. The separation between the $3 \mathrm{~d}_{5 / 2}$ and $3 \mathrm{~d}_{3 / 2}$ peaks of Mo was constrained to $3.2 \mathrm{eV}$ for the Mo-C peaks and $3 \mathrm{eV}$ for the oxide peaks. The area ratio of the $3 \mathrm{~d}_{5 / 2}$ to $3 \mathrm{~d}_{3 / 2}$ peaks was constrained to $3: 2$.

X-ray diffraction (XRD) patterns were recorded using a diffractometer (Rigaku Smart Lab, Tokyo, Japan) with $\mathrm{Cu} \mathrm{K}$ radiation (40 KV and $30 \mathrm{~mA}$ ), a step size of $0.05^{\circ}$, and dwell time of $1.5 \mathrm{~s}$, in the $2 \theta$ range of $3-65^{\circ}$.

Transmission electron microscopy (TEM) were performed at $120 \mathrm{keV}$ on a JEOL JEM2100 microscope.

\section{Results and Discussion}

XRD patterns of the parent MAX phases and their corresponding MXenes shown in Figure 1a confirm that the vacuum filtered MXene paper does not contain any residual MAX phase or other salt impurities. We can therefore attribute the electrochemical performance solely to the MXene. Further, the absence of any peak around $61^{\circ}$, which is attributed to the $<110>$ family of planes, indicates that the vast majority of the flakes are parallel to the substrate. In our previous 
work it has been shown that drop cast MXene sheets lie parallel to the substrate ${ }^{39}$. This orientation with respect to the substrate ensures that the majority of the catalytic activity can be attributed to the basal plane of the MXene. TEM images of typical $\mathrm{Mo}_{2} \mathrm{CT}_{\mathrm{z}}$ and $\mathrm{Mo}_{1.33} \mathrm{CT}_{\mathrm{z}}$ colloidal solids (Figs. 1b and c) confirm that they are indeed delaminated few or single layers. Analysis of the XPS spectra, Figure 2, of the drop cast films gives calculated Mo:C ratios of $1.30 \pm 0.1$ for $\mathrm{Mo}_{1.33} \mathrm{CT}_{\mathrm{z}}$ and $2 \pm 0.15$ for $\mathrm{Mo}_{2} \mathrm{CT}_{z}$ which is in agreement with the expected stoichiometry of the MXenes.

Figure 3a plots the anodic sweep of the HER polarization curves of $\mathrm{Mo}_{1.33} \mathrm{CT}_{\mathrm{z}}, \mathrm{Mo}_{2} \mathrm{CT}_{\mathrm{z}}$, and commercial $\mathrm{Pt} / \mathrm{C}$ catalyst. The HER activity of $\mathrm{Mo}_{1.33} \mathrm{CT}_{\mathrm{z}}$ is lower than $\mathrm{Mo}_{2} \mathrm{CT}_{\mathrm{z}}$, with overpotentials at $10 \mathrm{~mA} / \mathrm{cm}^{2}$ of 422 and $239 \mathrm{mV}$, respectively. The intrinsic per-site activity of $\mathrm{Mo}_{2} \mathrm{CT}_{\mathrm{z}}$ at low, and high, $\mathrm{pH}$ as a function of loading is reported as a turn over frequency (TOF) in Figure S4. To obtain these values we used the calculation procedure outlined by Seh et al. ${ }^{8}$, assuming all -O terminated Mo atoms to be active sites. At an overpotential of $200 \mathrm{mV}$ and loading of $0.1 \mathrm{mg} / \mathrm{cm}^{2}$, the TOF of $\mathrm{Mo}_{2} \mathrm{CT}_{\mathrm{z}}$ was found to be approximately $\sim 0.03 \mathrm{H}_{2} \mathrm{~s}^{-1}$ which is in line with previous results for $\mathrm{Mo}_{2} \mathrm{CT}_{\mathrm{z}}{ }^{8}$. In order to reach a similar TOF, $\mathrm{Mo}_{1.33} \mathrm{CT}_{\mathrm{z}}$ requires $\sim 392 \mathrm{mV}$ of overpotential.

General intuition would suggest an opposing trend to that observed for HER activity as a function of surface stoichiometry for the two different Mo-carbide MXenes. Intuitively, the addition of atomic scale vacancy defects, as highlighted in the high resolution transmission electron micrographs (HRTEM) in previous characterizations of $\mathrm{Mo}_{1.33} \mathrm{CT}_{\mathrm{z}}{ }^{31}$, would be expected to increase the activity due to a higher density of lower coordinated, more reactive sites and the intrinsic increase in conductivity and capacity that is observed for $\mathrm{Mo}_{1.33} \mathrm{CT}_{\mathrm{z}}{ }^{31}$. Previous DFT analysis of $\mathrm{Mo}_{2} \mathrm{CT}_{z}$ MXenes indicates that the lowest free energy of adsorption for $\mathrm{H}$ is on the $-\mathrm{O}$ termination of the surface, converting it to $-\mathrm{OH}^{8}$. This ostensibly makes the $-\mathrm{O}$ terminations on the surface the active sites. The -O terminated active sites can be further categorized by their particular geometry: bridge, on top, fcc, and hcp. H adsorption on -O terminated hcp sites is found to have the lowest free energy of adsorption ${ }^{8}$. This is an indication that hep coordination is the desired active site geometry. Figure 4 displays the atomic geometry and coordination of both $\mathrm{Mo}_{2} \mathrm{CT}_{\mathrm{z}}$ and $\mathrm{Mo}_{1.33} \mathrm{CT}_{\mathrm{z}}$ from a top and in-plane view. Central to the hep site in $\mathrm{Mo}_{2} \mathrm{CT}_{\mathrm{z}}$ is a six-fold coordinated $\mathrm{C}$ atom, Figure $4 \mathrm{~b}$. The introduction of divacancies in $\mathrm{Mo}_{1.33} \mathrm{CT}_{\mathrm{z}}$ changes the distribution of coordination geometries on the surface. From the structural models in Figure $4 \mathrm{c}$ and $\mathrm{d}$, it is clear that there are no longer any hcp sites with a central 6-fold coordinated $\mathrm{C}$ atom. In fact, there are 
no six-fold coordinated $\mathrm{C}$ atoms in the entire structure. We argue that it is this loss in the optimal H-adsorption site coordination and geometry that defines the observed lower activity on $\mathrm{Mo}_{1.33} \mathrm{CT}_{\mathrm{z}}$. The cathodic shift in the onset potential for the reaction, when comparing $\mathrm{Mo}_{2} \mathrm{CT}_{\mathrm{z}}$ to $\mathrm{Mo}_{1.33} \mathrm{CT}_{\mathrm{z}}$, points to a weakening of $\mathrm{H}$ adsorption, which would put $\mathrm{Mo}_{1.33} \mathrm{CT}_{\mathrm{z}}$ lower on the right leg of the activity volcano ${ }^{8}$. These combined effects provide an explanation for the observed dependence of HER activity on MXene stoichiometry and surface atomic structure.

The operational stabilities of the $\mathrm{Mo}_{1.33} \mathrm{CT}_{\mathrm{z}}$ and $\mathrm{Mo}_{2} \mathrm{CT}_{\mathrm{z}}$ electrodes are assessed through an accelerated durability testing (ADT) load cycling protocol $\left(\mathrm{H}_{2}\right.$ saturated $0.1 \mathrm{M} \mathrm{HClO}_{4}, 1600$ $\mathrm{rpm}, 50 \mathrm{mV} / \mathrm{s},-0.6$ to $0.1 \mathrm{~V}$ vs. RHE). Figure $3 \mathrm{~b}$ shows the anodic sweep of the HER polarization curves pre- and post-ADT for both electrodes. Both $\mathrm{Mo}_{2} \mathrm{CT}_{\mathrm{z}}$ and $\mathrm{Mo}_{1.33} \mathrm{CT}_{\mathrm{z}}$ are found to decrease in activity after $1000 \mathrm{ADT}$ cycles $\left(\sim 60 \mathrm{mV}\right.$ increase in overpotential at $10 \mathrm{~mA} / \mathrm{cm}^{2}$ after 1000 ADT cycles). While the stoichiometry and surface coordinations are different for the two MXenes tested, the observed degree of activity decay appears to be comparable.

XPS both pre- and post-ADT is used to assess the change in surface chemistry with potential cycling. Spectra are recorded for as-made, after 3 reductive cycles, and after 1000 ADT cycles in $0.1 \mathrm{M} \mathrm{HClO}_{4}$. Figures $2 \mathrm{a}$ to $\mathrm{c}$ show the high-resolution XPS spectra of the Mo $3 \mathrm{~d}$ region for the $\mathrm{Mo}_{2} \mathrm{CT}_{\mathrm{z}}$ electrodes and Figures $2 \mathrm{~d}$ to f plot the same for the $\mathrm{Mo}_{1.33} \mathrm{CT}_{\mathrm{z}}$ electrodes. In both cases, the fitting was based on the assignment of the peak at $228.5 \mathrm{eV}$ to the Mo-C moiety in the MXene. The peak at $\sim 232 \mathrm{eV}$ is due to both Mo-C and $\mathrm{Mo}^{6+}$, and that at $\sim 235 \mathrm{eV}$ is due to $\mathrm{Mo}^{6+}$ only $^{31,34,38,40}$. In both cases, the relative area of the latter peak increases with cycling, indicating a slow oxidation of the MXenes during HER ADT cycling. This conclusion is consistent with that of Kang et al. who also observed oxidation of commercial $\mathrm{Mo}_{2} \mathrm{C}$ powders during $\mathrm{HER}^{41}$. Table 1 summarizes the XPS peak fitting results. A general increase in the proportion of higher valent Mo species is observed for both $\mathrm{Mo}_{2} \mathrm{CT}_{\mathrm{z}}$ and $\mathrm{Mo}_{1.33} \mathrm{CT}_{\mathrm{z}}$ after $1000 \mathrm{ADT}$ cycles. This is a direct indication of the oxidation of the MXene during HER and the argued source of activity loss during ADT. Both the increase in overpotential, Figure $3 \mathrm{~b}$, and the increase in higher valent $\mathrm{Mo}^{6+}$ species are similar for the two stoichiometries tested. This is an indication that both the degree and mechanism of degradation is the same and independent of initial surface structure. These results are in seeming contradiction to what would be expected for catalyst operation at reductive conditions. For PGM materials, a relative $\mathrm{pH}$ insensitive operational stability is assumed when the upper potential limit is kept below the potential for the initiation of anodic dissolution. This 
inherent stability at cathodic electrolysis conditions is often assumed to translate to non-PGM materials, especially if the operational potentials remain below those that would initiate anodic corrosion of the parent metal of the non-PGM catalyst. The results presented here highlight the need to more carefully assess the operational stability of any newly developed, non-PGM catalysts even for operation under reductive conditions as they may still be susceptible to oxidation and/or hydrolysis.

The strong $\mathrm{pH}$ dependence of the reversible hydrogen reaction is well established for $\mathrm{Pt}$ and other transition metal catalysts ${ }^{1,37,42-46}$. The exchange current density, a measure of the intrinsic reaction rate, for the reversible $\mathrm{H}_{2}$ reaction on $\mathrm{Pt}$ is several orders of magnitude lower at pH 13 compared to $\mathrm{pH} 1^{1,37,42-46}$. In Figure 5, we observe a pH independence of the HER activity on both $\mathrm{Mo}_{2} \mathrm{CT}_{2}$ and $\mathrm{Mo}_{1.33} \mathrm{CT}_{2}$, when normalized to the reversible hydrogen electrode. This $\mathrm{pH}$ universal HER activity has been demonstrated for other non-PGM materials ${ }^{47,48}$. However, its origin is not fully understood. Current controversy surrounding the $\mathrm{pH}$ dependent activity and mechanism of the $\mathrm{H}$ reactions ${ }^{37}$ complicates any true assessment of the source of this $\mathrm{pH}$ universal behavior. In Figure 5, while the HER activity is essentially identical at both $\mathrm{pH} 1$ and $\mathrm{pH}$ 13, a slight difference is observed where both stoichiometries are found to be more active at $\mathrm{pH} 13$.

Previous work on $\mathrm{Mo}_{2} \mathrm{CT}_{\mathrm{z}}$ and $\mathrm{Ti}_{2} \mathrm{CT}_{\mathrm{z}}$ has demonstrated the impact of surface $\mathrm{F}$ passivation on HER activity. For $\mathrm{Ti}_{2} \mathrm{CT}_{\mathrm{z}}$, the initial HER activity, at $\mathrm{pH} 1$, has an overpotential of $\sim 900 \mathrm{mV}$ at $10 \mathrm{~mA} / \mathrm{cm}^{2}{ }^{19}$. The observed overpotential at $\mathrm{pH} 13$, however, is significantly lower at $\sim 675 \mathrm{mV}$. Following potential cycling in a $\mathrm{pH} 13$ electrolyte, the HER overpotential dramatically decreases at $\mathrm{pH} \mathrm{1,} \mathrm{matching} \mathrm{that} \mathrm{observed} \mathrm{at} \mathrm{pH} 13$. Post-mortem XPS analysis indicates that the assynthesized $\mathrm{Ti}_{2} \mathrm{CT}_{\mathrm{z}}$ has a high $-\mathrm{F}$ termination content while that after potential cycling at $\mathrm{pH} 13$ is significantly lower. It was thus concluded that cycling in $\mathrm{pH} 13$ electrolyte effectively removes surface $-\mathrm{F}$ species, freeing active sites and resulting in the dramatic decrease in overpotential ${ }^{19}$. Figure 6 shows the $\mathrm{F} 1 \mathrm{~s}$ XPS spectra for $\mathrm{Mo}_{2} \mathrm{CT}_{\mathrm{z}}$ and $\mathrm{Mo}_{1.33} \mathrm{CT}_{\mathrm{z}}$ as-synthesized, after 3 cycles, and after $1000 \mathrm{ADT}$ cycles in $0.1 \mathrm{M} \mathrm{HClO}_{4}$. Following similar synthesis procedures, $\mathrm{Mo}_{2} \mathrm{CT}_{\mathrm{z}}$ is found to have a $\mathrm{F} / \mathrm{Mo}$ ratio of 0.13 , while that for $\mathrm{Mo}_{1.33} \mathrm{CT}_{\mathrm{z}}$ is considerably larger at 0.92 . Following three quick cycles in $0.1 \mathrm{M} \mathrm{HClO}_{4}$, the $\mathrm{Mo}_{2} \mathrm{CT}_{\mathrm{z}}$ and $\mathrm{Mo}_{1.33} \mathrm{CT}_{\mathrm{z}} \mathrm{F} / \mathrm{Mo}$ ratios drastically decrease to 0.03 and 0.38 , respectively. After ADT testing, no measurable $-\mathrm{F}$ terminations are remaining. We observe no increase, or change, in HER activity for $\mathrm{Mo}_{1.33} \mathrm{CT}_{\mathrm{z}}$ during the early ADT cycles while the XPS indicates a significant decrease in the -F surface coverage. This demonstrates that while 
the initial $\mathrm{F} / \mathrm{Mo}$ ratio is significantly higher for $\mathrm{Mo}_{1.33} \mathrm{CT}_{\mathrm{z}}$, removal of that $-\mathrm{F}$ does not result in any increase in activity. Thus, we conclude that the difference in initial and final HER activity between $\mathrm{Mo}_{2} \mathrm{CT}_{\mathrm{z}}$ and $\mathrm{Mo}_{1.33} \mathrm{~T}_{\mathrm{z}}$ is not due to the difference in $\mathrm{F} / \mathrm{Mo}$ ratio, but rather some intrinsic property of the material surface.

\section{Conclusions}

In summary, we have shown that Mo based MXenes show promise as HER catalytic materials with a $\mathrm{pH}$ universal activity and sufficient operational durability. MXene stoichiometry and atomic surface structure is found to be critically important for catalytic activity, however, it is found to have less of an impact on operational durability. $\mathrm{Mo}_{1.33} \mathrm{CT}_{\mathrm{z}}$ possessing ordered surface divacancies, is less active for the HER than $\mathrm{Mo}_{2} \mathrm{CT}_{\mathrm{z}}$ which is attributed to changes in both the electronic properties of the surface, as well as a decrease in the proportion of the optimal -O terminated, hep sites with a central six-fold coordinated $\mathrm{C}$ atom. This work provides important insight for the design and development of Mo-based 2D materials as effective catalysts for HER with potential application to other technologically relevant electrochemical reactions including oxygen evolution, oxygen reduction, and carbon dioxide reduction.

\section{References}

1. Sheng, W., Zhuang, Z., Gao, M., Zheng, J., Chen, J., Yan, Y. Correlating hydrogen oxidation and evolution activity on platinum at different $\mathrm{pH}$ with measured hydrogen binding energy. Nat. Commun. 6, 5848 (2015).

2. Benck, J., Chen, Z., Kuritzky, L., Forman, A., Jaramillo, T. Amorphous molybdenum sulfide catalysts for electrochemical hydrogen production: Insights into the origin of their catalytic activity. ACS Catal. 2, 1916-1923 (2012).

3. Siqi, L., Zhongbin, Z. Electrocatalysts for hydrogen oxidation and evolution reactions. Sci. China Mater. 59, 217-238 (2016).

4. Feng, Y., Gong, S., Du, E., Chen, X., Qi, R., Yu, K., Zhu, Z. 3R TaS2 Surpasses the Corresponding 1T and 2H Phases for the Hydrogen Evolution Reaction. J. Phys. Chem. C 122, 2382-2390 (2018).

5. Faber, M., Dziedzic, R., Lukowski, M., Kaiser, N., Ding, Q., Jin, S. High-performance electrocatalysis using metallic cobalt pyrite $(\mathrm{CoS} 2)$ micro- and nanostructures. J. Am. Chem. Soc. 136, 10053-10061 (2014).

6. Li, Y., Polakovic, T., Curtis, J., Shumlas, S., Chatterjee, S., Intikhab, S., Chareev, D., Volkova, O., Vasiliev, A., Karapetrov, K., Snyder, J. Tuning the activity/stability balance of anion doped CoSxSe2-xdichalcogenides. J. Catal. 366, 50-60 (2018). 
7. Chen, W., Sasaki, K., Ma, C., Frenkel, A., Marinkovic, N., Muckerman, J., Zhu, Y., Adzic, R. Hydrogen-Evolution Catalysts Based on Non-Noble Metal Nickel Molybdenum Nitride Nanosheets. Angew. Chem. Int. Ed. 51, 6131-6135 (2012).

8. Seh, Z., Fredrickson, K., Anasori, B., Kibsgaard, J., Strickler, A., Lukatskaya, M., Gogotsi, Y., Jaramillo, T., Vojvodic, A. Two-Dimensional Molybdenum Carbide (MXene) as an Efficient Electrocatalyst for Hydrogen Evolution. ACS Energy Lett. 1, 589-594 (2016).

9. Vrubel, H., Hu, X. Molybdenum Boride and Carbide Catalyze Hydrogen Evolution in both Acidic and Basic Solutions. Angew. Chemie 124, 12875-12878 (2012).

10. Kibsgaard, J., Jaramillo, T. Molybdenum Phosphosulfide: An active, acid-stable, earthabundant catalyst for the hydrogen evolution reaction. Angew. Chem. Int. Ed. 53, 1443314437 (2014).

11. Popczun, E., Read, C., Roske, C., Lewis, N., Schaak, R. Highly Active Electrocatalysis of the Hydrogen Evolution Reaction by Cobalt Phosphide Nanoparticles. Angew. Chem. Int. Ed. 53, 5427-5430 (2014).

12. Zhang, K., Zhang, G., Qu, J., Liu, H. Tungsten-Assisted Phase Tuning of Molybdenum Carbide for E ffi cient Electrocatalytic Hydrogen Evolution. ACS Appl. Mater. Interfaces 10, 2451-2459 (2018).

13. Wan, C., Regmi, Y., Leonard, B. Multiple Phases of Molybdenum Carbide as Electrocatalysts for the Hydrogen Evolution Reaction. Angew. Chemie 126, 6525-6528 (2014).

14. Miao, M., Pan, J., He, T., Yan, Y., Xia, B., Wang, X. Molybdenum Carbide-Based Electrocatalysts for Hydrogen Evolution Reaction. Chem. - A Eur. J. 23, 10947-10961 (2017).

15. Du, C., Huang, H., Wu, Y., Wu, S., Song, W. Ultra-efficient electrocatalytic hydrogen evolution at one-step carbonization generated molybdenum carbide nanosheets/ $\mathrm{N}$-doped carbon. Nanoscale 8, 16251-16258 (2016).

16. Ang, H., Tan, H., Luo, Z., Zhang, Y., Gu, Y., Guo, G., Zhang, H., Yan, Q. Hydrophilic Nitrogen and Sulfur Co-doped Molybdenum Carbide Nanosheets for Electrochemical Hydrogen Evolution. Small 11, 6278-6284 (2015).

17. Naguib, M., Kurtoglu, M., Presser, V., Lu, J., Niu, J., Heon, M., Hultman, L., Gogotsi, Y., Barsoum, M. Two-Dimensional Nanocrystals Produced by Exfoliation of Ti3AlC2. Adv. Mater. 23, 4248-4253 (2011).

18. Naguib, M., Mochalin, V., Barsoum, M., Gogotsi, Y. 25th Anniversary Article: MXenes: A New Family of Two-Dimensional Materials. Adv. Mater. 26, 992-1005 (2014).

19. Handoko, A., Fredrickson, K., Anasori, B., Convey, K., Johnson, L., Gogotsi, Y., Vojvodic, A., Seh, Z. Tuning the Basal Plane Functionalization of Two-Dimensional Metal Carbides (MXenes) To Control Hydrogen Evolution Activity. ACS Appl. Energy Mater. 1, 173-180 (2018). 
20. Pan, H. Ultra-high electrochemical catalytic activity of MXenes. Sci. Rep. 6, 32531 (2016).

21. Alameda, L., Holder, C., Fenton, J., Schaak, R. Partial Etching of Al from MoAlB Single Crystals To Expose Catalytically Active Basal Planes for the Hydrogen Evolution Reaction. Chem. Mater. 29, 8953-8957 (2017).

22. Li, F., Zhao, X., Mahmood, J., Okyay, M., Jung, S., Ahmad, I., Kim, S., Han, G., Park, N., Baek, J. Macroporous Inverse Opal-like MoxC with Incorporated Mo Vacancies for Significantly Enhanced Hydrogen Evolution. ACS Nano 11, 7527-7533 (2017).

23. Grozovski, V., Climent, V., Herrero, E., Feliu, J. Intrinsic activity and poisoning rate for $\mathrm{HCOOH}$ oxidation at $\mathrm{Pt}(100)$ and vicinal surfaces containing monoatomic (111) steps. ChemPhysChem 10, 1922-1926 (2009).

24. Lin, W., Zei, M., Eiswirth, M., Ertl, G., Iwasita, T., Vielstich, W. Electrocatalytic Activity of Ru-Modified Pt (111) Electrodes toward CO Oxidation. J. Phys. Chem. B 103, 69686977 (1999).

25. Garcia, G., Koper, M. Mechanism of electro-oxidation of carbon monoxide on stepped platinum electrodes in alkaline media: a chronoamperometric and kinetic modeling study. Phys. Chem. Chem. Phys. 11, 11437 (2009).

26. Markovic, N., Grgur, B., Lucas, C., Ross, P. Surface electrochemistry of CO on Pt(110)$(1 \times 2)$ and Pt(110)-(1×1) surfaces. Surf. Sci. 384, L805-L814 (1997).

27. Housmans, T., Koper, M. Methanol Oxidation on Stepped Pt[n(111) - (110)] Electrodes: A Chronoamperometric Study. J. Phys. Chem. B 107, 8557-8567 (2003).

28. Lebedeva, N., Koper, M., Feliu, J., van Santen, R. Role of crystalline defects in electrocatalysis: Mechanism and kinetics of CO adlayer oxidation on stepped platinum electrodes. J. Phys. Chem. B 106, 12938-12947 (2002).

29. Farias, M., Herrero, E., Feliu, J. Site selectivity for CO adsorption and stripping on stepped and kinked platinum surfaces in alkaline medium. J. Phys. Chem. C 117, $2903-$ 2913 (2013).

30. Colmati, F., Tremiliosi-Filho, G., Gonzalez, E., Berna, A., Herrero, E., Feliu, J. The role of the steps in the cleavage of the C-C bond during ethanol oxidaiton on platinum electrodes. Phys. Chem. Chem. Phys. 11, 9114-9123 (2009).

31. Tao, Q., Dahlqvist, M., Lu, J., Sankalp, K., Meshkian, R., Halim, J., Palisaitis, J., Hultman, L., Barsoum, M., Persson, P., Rosen, J. Two-dimensional Mo1.33C MXene with divacancy ordering prepared from parent 3D laminate with in-plane chemical ordering. Nat. Commun. 8, 14949 (2017).

32. Meshkian, R., Dahlqvist, M., Lu, J., Wickman, B., Halim, J., Thornberg, J., Tao, Q., Li, S., Intikhab, S., Snyder, J., Barsoum, M., Yildizhan, M., Palisaitis, J., Hultman, L., Persson, P., Rosen, J. W-Based Atomic Laminates and Their 2D Derivative W1.33C MXene with Vacancy Ordering. Adv. Mater. 30, 1706409 (2018).

33. Dahlqvist, M., Lu, J., Meshkian, R., Tao, Q., Hultman, L., Rosen, J. Prediction and 
synthesis of a family of atomic laminate phases with Kagomé-like and in-plane chemical ordering. Sci. Adv. 3, e1700642 (2017).

34. Lind, H., Halim, J., Simak, S., Rosen, J. Investigation of vacancy-ordered Mo1.33C MXene from first principles and x-ray photoelectron spectroscopy. Phys. Rev. Mater. 1, 044002 (2017).

35. Persson, I., Ghazaly, A., Tao, Q., Halim, J., Kota, S., Darakchieva, V., Palisaitis, J., Barsoum, M., Rosen, J., Persson, P. Tailoring Structure, Composition, and Energy Storage Properties of MXenes from Selective Etching of In-Plane, Chemically Ordered MAX Phases. Small 14, 1703676 (2018).

36. Dahlqvist, M., Petruhins, A., Lu, J., Hultman, L., Rosen, J. Origin of Chemically Ordered Atomic Laminates (i-MAX): Expanding the Elemental Space by a Theoretical/Experimental Approach. ACS Nano (2018). doi:10.1021/acsnano.8b01774

37. Intikhab, S., Snyder, J., Tang, M. Adsorbed Hydroxide Does Not Participate in the Volmer Step of Alkaline Hydrogen Electrocatalysis. ACS Catal. 7, 8314-8319 (2017).

38. Halim, J., Kota, S., Lukatskaya, M., Naguib, M., Zhao, M., Moon, E., Pitock, J., Nanda, J., May, S., Gogotsi, Y., Barsoum, M. Synthesis and Characterization of 2D Molybdenum Carbide (MXene). Adv. Funct. Mater. 26, 3118-3127 (2016).

39. Zhao, D., Clites, M., Ying, G., Kota, S., Wang, J., Natu, V., Wang, X., Pomerantseva, E., Cao, M., Barsoum, M. Alkali-induced crumpling of Ti3C2Tx (MXene) to form 3D porous networks for sodium ion storage. Chem. Commun. 54, 4533-4536 (2018).

40. Halim, J., Cook, K., Naguib, M., Edlund, P., Gogotsi, Y., Rosen, J., Barsoum, M. X-ray photoelectron spectroscopy of select multi-layered transition metal carbides (MXenes). Appl. Surf. Sci. 362, 406-417 (2016).

41. Kang, J., Kim, J., Lee, M., Son, Y., Chung, D., Park, S., Jeong, J., Yoo, J., Shin, H., Choe, H., Park, H., Sung, Y. Electrochemically Synthesized Nanoporous Molybdenum Carbide as a Durable Electrocatalyst for Hydrogen Evolution Reaction. Adv. Sci. 5, 1700601 (2018).

42. Ledezma-Yanez, I., Wallace, W., Sebastian-Pascual, P., Climent, V., Feliu, J., Koper, M. Interfacial water reorganization as a $\mathrm{pH}$-dependent descriptor of the hydrogen evolution rate on platinum electrodes. Nat. Energy 2, 17031 (2017).

43. Zheng, J., Nash, J., Xu, B., Yan, Y. Towards Establishing Apparent Hydrogen Binding Energy as the Descriptor for Hydrogen Oxidation/Evolution Reactions. J. Electrochem. Soc. 165, H27-H29 (2018).

44. Sheng, W., Myint, M., Chen, J., Yan, Y. Correlating the hydrogen evolution reaction activity in alkaline electrolytes with the hydrogen binding energy on monometallic surfaces. Energy Environ. Sci. 6, 1509-1512 (2013).

45. Sheng, W., Gasteiger, H., Shao-Horn, Y. Hydrogen Oxidation and Evolution Reaction Kinetics on Platinum: Acid vs Alkaline Electrolytes. J. Electrochem. Soc. 157, B1529B1536 (2010). 
46. Strmcnik, D., Uchimura, M., Wang, C., Subbaraman, R., Danilovic, N., van der Vliet, D., Paulikas, A., Stamenkovic, V., Markovic, N. Improving the hydrogen oxidation reaction rate by promotion of hydroxyl adsorption. Nat. Chem. 5, 300-306 (2013).

47. Zhang, X., Yu, X., Zhang, L., Zhou, F., Liang, Y., Wang, R. Molybdenum Phosphide / Carbon Nanotube Hybrids as pH-Universal Electrocatalysts for Hydrogen Evolution Reaction. Adv. Funct. Mater. 28, 1706523 (2018).

48. Li, G., Zhang, D., Yu, Y., Huang, S., Yang, W., Cao, L. Activating MoS2 for pHUniversal Hydrogen Evolution Catalysis. J. Am Chem. Soc. 139, 16194-16200 (2017).

\section{Acknowledgements}

J.S. and S.I. acknowledge support from NSF CBET-Catalysis under grant 1602886. J.R. acknowledge the Swedish Research Council for funding under grant no. 642-2013-8020, and the Knut and Alice Wallenberg (KAW) Foundation for a Fellowship grant. J.R. and M.B. also acknowledge the Swedish Foundation for Strategic Research (SSF) through project funding (EM16-0004). 


\section{Figures}
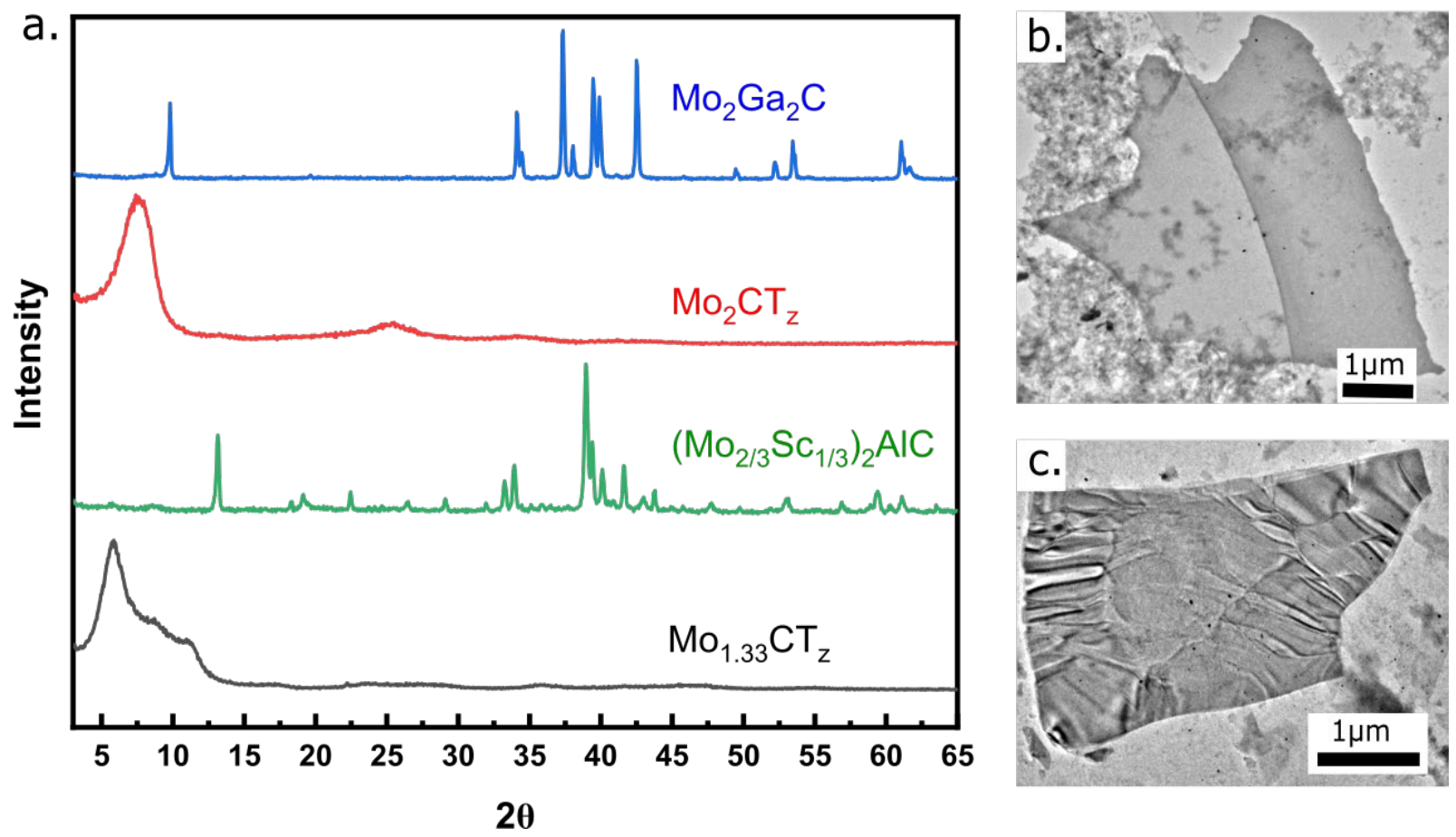

Figure 1: (a) XRD patterns of $\mathrm{Mo}_{2} \mathrm{Ga}_{2} \mathrm{C}$ MAX phase (blue), $\mathrm{Mo}_{2} \mathrm{CT}_{\mathrm{z}}$ paper (red), $\left(\mathrm{Mo}_{2 / 3} \mathrm{Sc}_{1 / 3}\right)_{2} \mathrm{AlC}$ MAX phase (green) and $\mathrm{Mo}_{1.33} \mathrm{CT}_{\mathrm{z}}$ paper (black). TEM images of (b) $\mathrm{Mo}_{2} \mathrm{CT}_{\mathrm{z}} \mathrm{MXene}$ flake and (c) $\mathrm{Mo}_{1.33} \mathrm{CT}_{\mathrm{z}}$ MXene flake. 

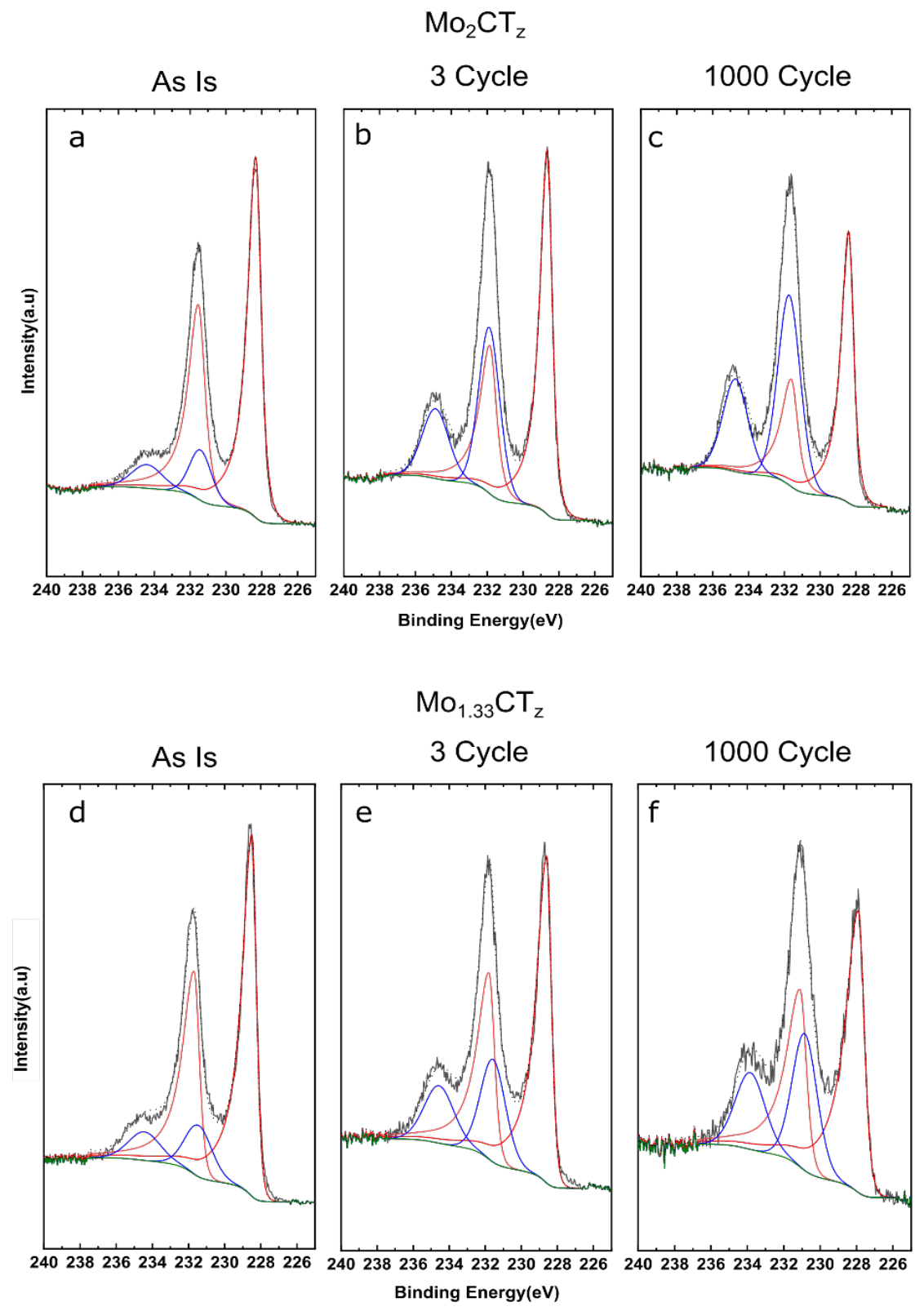

Experimental $\longrightarrow \mathrm{C}-\mathrm{Mo}_{\mathrm{z}}-\mathrm{Mo}^{+6} \longrightarrow$ Background $\cdots \cdots \cdots . .$. Fit

Figure 2: XPS of Mo 3d region for $\mathrm{Mo}_{2} \mathrm{CT}_{z}$, (a) as-received prior to cycling, (b) after 3 and, (c) after $1000 \mathrm{ADT}$ cycles and for $\mathrm{Mo}_{1.33} \mathrm{CT}_{\mathrm{z}}$, (d) as-received prior to cycling, (e) after 3 and, (f) after 1000 ADT cycles. All cycling was completed in $\mathrm{H}_{2}$ saturated $0.1 \mathrm{M} \mathrm{HClO}_{4}$. 

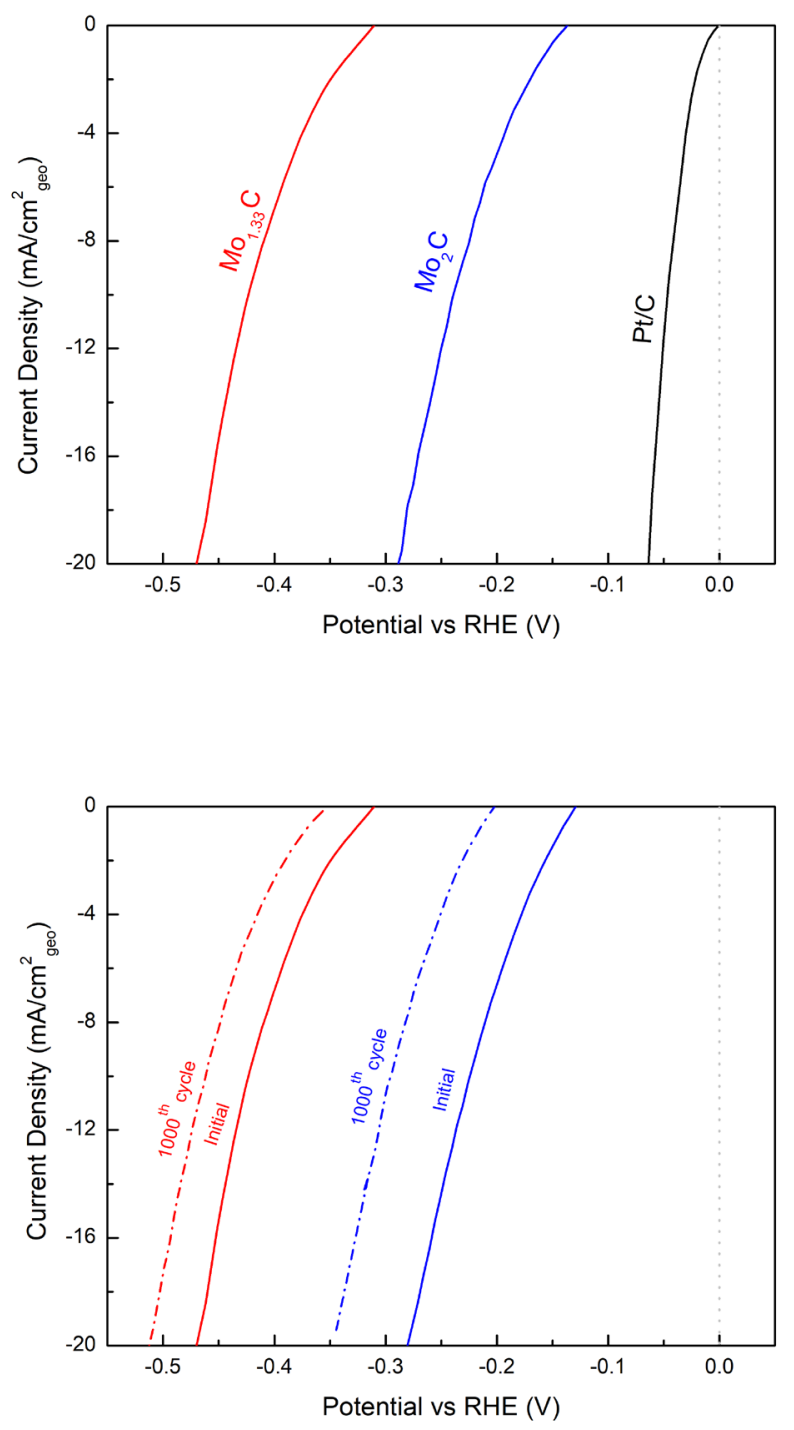

Figure 3: (a) HER activity of MXene: Polarization curves for $\mathrm{Mo}_{1.33} \mathrm{CT}_{\mathrm{z}}$ (red), $\mathrm{Mo}_{2} \mathrm{CT}_{\mathrm{z}}$ (blue) (mass loading: $0.1 \mathrm{mg} / \mathrm{cm}^{2}$ ), and $\mathrm{Pt} / \mathrm{C}$ (black) (Pt loading: $15 \mu \mathrm{g} / \mathrm{cm}^{2}$ ) in $\mathrm{H}_{2}$ saturated $0.1 \mathrm{M} \mathrm{HClO}_{4}$ measured at a scan rate of $50 \mathrm{mV} / \mathrm{s}$ and rotation rate of $1600 \mathrm{rpm}$. (b) Polarization curves for $\mathrm{Mo}_{1.33} \mathrm{CT}_{\mathrm{z}}$ (red), $\mathrm{Mo}_{2} \mathrm{CT}_{\mathrm{z}}$ (blue) (mass loading: $0.1 \mathrm{mg} / \mathrm{cm}^{2}$ ) before (solid) and after (dashed) 1000 ADT cycles $\left(\mathrm{H}_{2}\right.$ saturated $0.1 \mathrm{M} \mathrm{HClO}_{4}, 1600 \mathrm{rpm}, 50 \mathrm{mV} / \mathrm{s},-0.6$ to $0.1 \mathrm{~V}$ vs. RHE). 


\section{$\mathrm{Mo}_{2} \mathrm{C}$ MXene}

a.

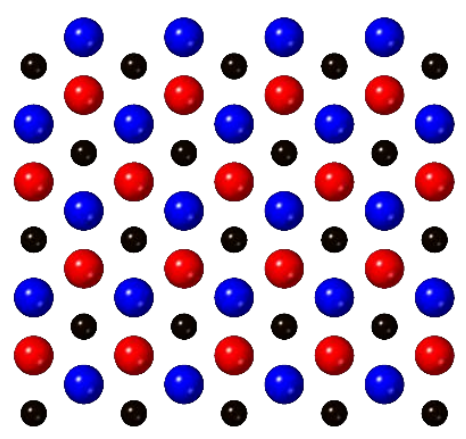

b.

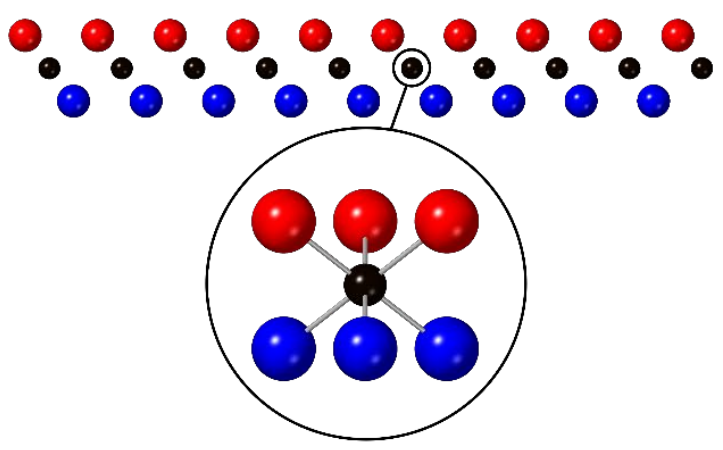

$\mathrm{Mo}_{1.33} \mathrm{C}$ MXene

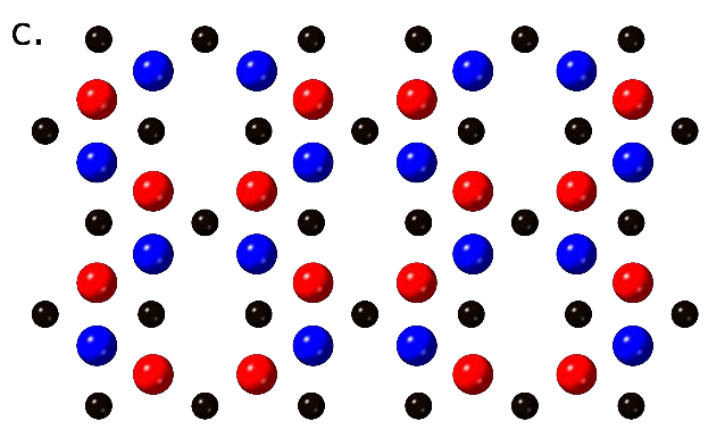

d.

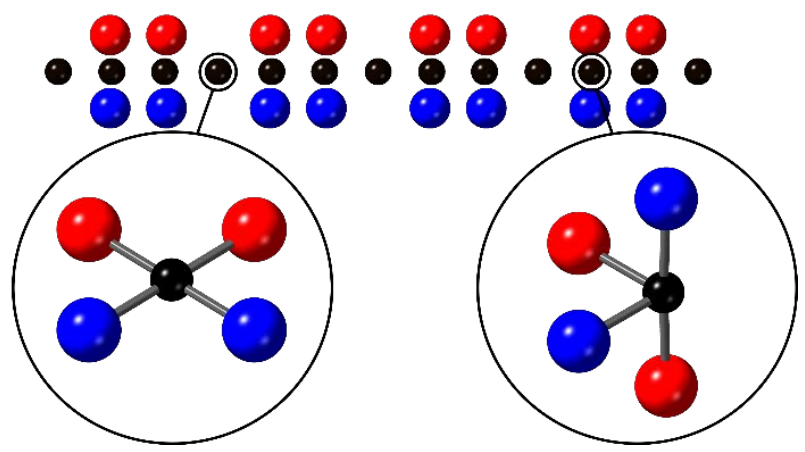

Figure 4: $\mathrm{Mo}_{2} \mathrm{C}$ MXene: (a) top view (along c-direction) and (b) side view (along b-direction); $\mathrm{Mo}_{1.33} \mathrm{C}$ MXene: (c) top view (along c-direction) and (d) side view (along b-direction). The insets in (b) and (d) show the bonding and coordination of carbon to Mo for the different MXene stoichiometries. The Mo atoms in the top (red) and bottom (blue) layer with respect to carbon are color coded for differentiation in the top view, (a) and (c). 


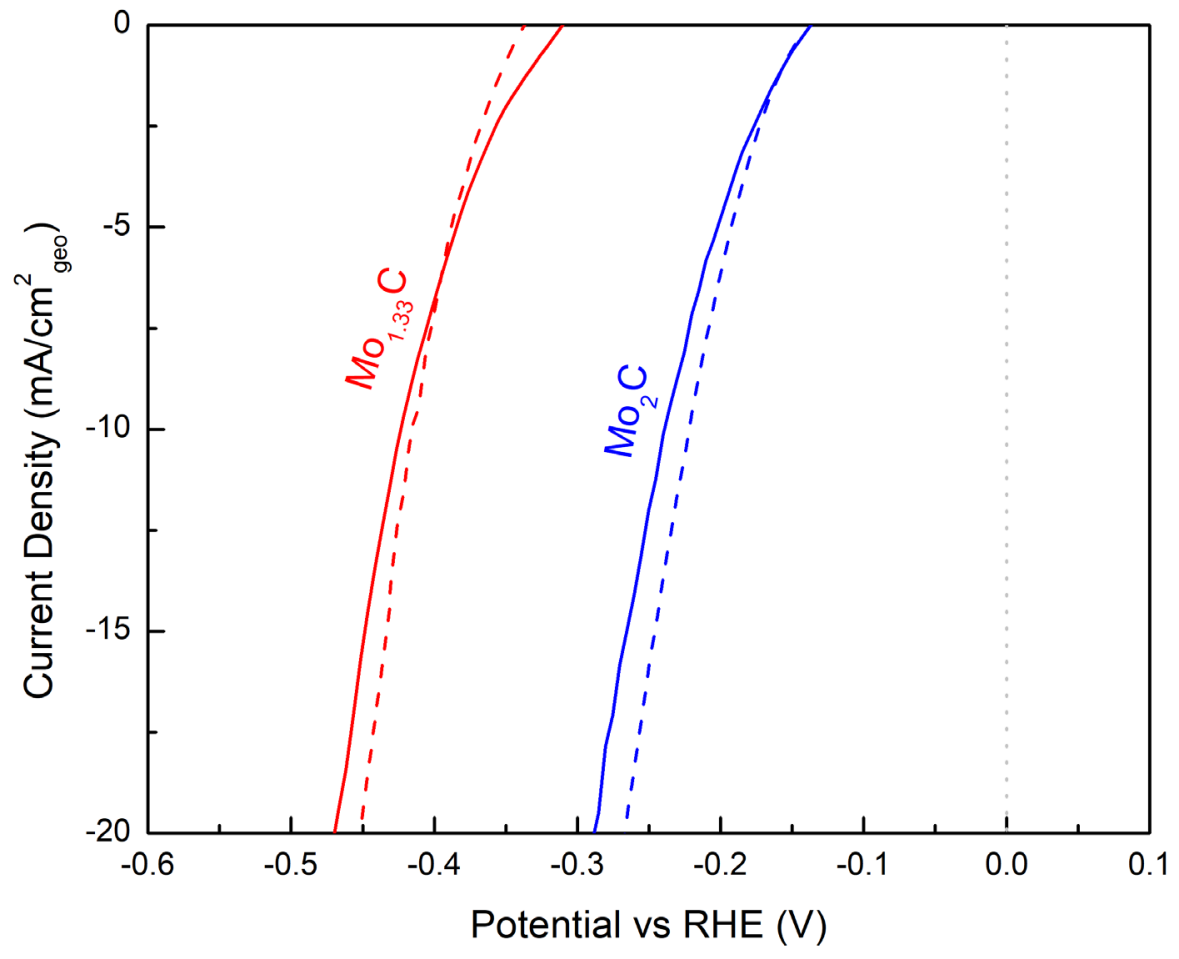

Figure 5: $\mathrm{pH}$ universal HER activity of MXenes: Polarization curves for $\mathrm{Mo}_{1.33} \mathrm{CT}_{\mathrm{z}}$ (red) and $\mathrm{Mo}_{2} \mathrm{CT}_{\mathrm{z}}$ (blue) (mass loading: $0.1 \mathrm{mg} / \mathrm{cm}^{2}$ ) in $\mathrm{H}_{2}$ saturated $0.1 \mathrm{M} \mathrm{HClO}_{4}$ (solid line) and $0.1 \mathrm{M}$ $\mathrm{KOH}$ (dashed line) measured at a scan rate of $50 \mathrm{mV} / \mathrm{s}$ and rotation rate of $1600 \mathrm{rpm}$. 


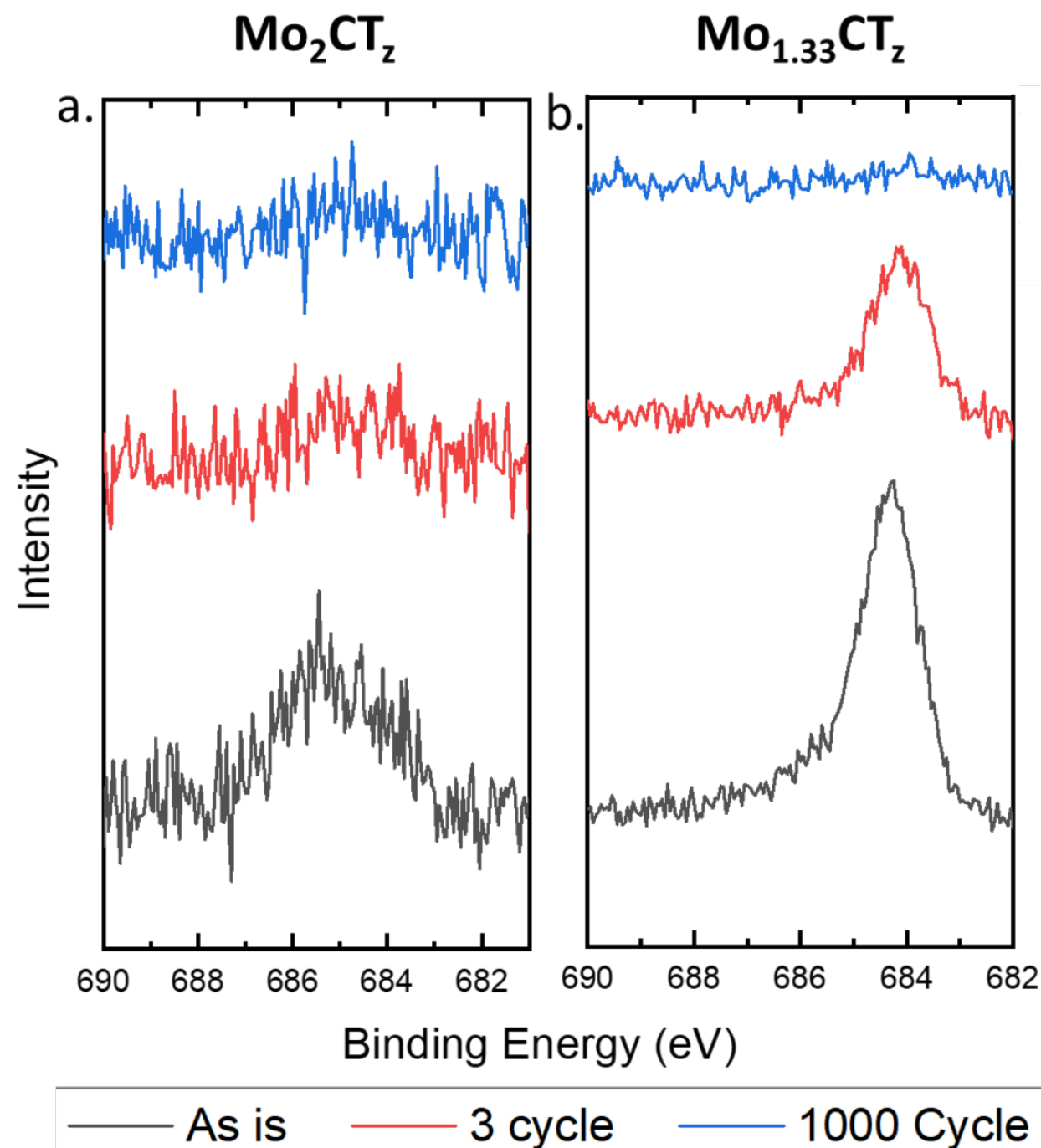

Figure 6: XPS spectra of $\mathrm{F}$ 1s spectra of, a) $\mathrm{Mo}_{2} \mathrm{CT}_{\mathrm{z}}$ and b) $\mathrm{Mo}_{1.33} \mathrm{CT}_{\mathrm{z}}$. Black (bottom) line is $\mathrm{F}$ spectra of as-received samples, red (middle) is after 3 cycles, blue (top) is after 1000 cycles. 
Table 1: Summary of XPS peak fittings shown in Figure 3 for $\mathrm{Mo}_{2} \mathrm{CT}_{\mathrm{z}}$ and $\mathrm{Mo}_{1.33} \mathrm{CT}_{\mathrm{z}}$. The numbers in brackets in column 2 are peak locations for Mo $3 \mathrm{~d}_{3 / 2}$ and full width at half maximum (FWHM) values for Mo $3 \mathrm{~d}_{3 / 2}$ peaks are in brackets in column 3 . The binding energy (BE) and the FWHM values for the Mo $3 \mathrm{~d}_{5 / 2}$ peaks are in column 2 and 3 respectively but outside of the brackets.

\begin{tabular}{|c|c|c|c|c|c|}
\hline Sample & $\mathrm{BE}(\mathrm{eV})$ & FWHM(eV) & Fraction & Assigned To & References \\
\hline $\begin{array}{c}\mathrm{Mo}_{2} \mathrm{CT}_{\mathrm{z}} \\
\text { (as-received) }\end{array}$ & $\begin{array}{l}228.3(231.5) \\
231.4(234.4)\end{array}$ & $\begin{array}{l}0.7(0.9) \\
1.4(2.0)\end{array}$ & $\begin{array}{l}0.85 \\
0.15\end{array}$ & $\begin{array}{c}\mathrm{C}^{-M o-T_{x}} \\
\mathrm{Mo}^{+6}\end{array}$ & 38 \\
\hline $\begin{array}{c}\mathrm{Mo}_{2} \mathrm{CT}_{\mathrm{z}} \\
\text { (3 cycles) }\end{array}$ & $\begin{array}{l}228.6(231.8) \\
231.8(234.8)\end{array}$ & $\begin{array}{l}0.6(0.8) \\
1.3(1.7)\end{array}$ & $\begin{array}{l}0.65 \\
0.35\end{array}$ & $\begin{array}{c}\mathrm{C}-\mathrm{Mo}^{-\mathrm{T}_{\mathrm{x}}} \\
\mathrm{Mo}^{+6}\end{array}$ & 38 \\
\hline $\begin{array}{c}\mathrm{Mo}_{2} \mathrm{CT}_{\mathrm{z}} \\
\text { (1000 cycles) }\end{array}$ & $\begin{array}{l}228.4(231.6) \\
231.7(234.7)\end{array}$ & $\begin{array}{l}0.7(0.9) \\
1.4(1.6)\end{array}$ & $\begin{array}{l}0.57 \\
0.43\end{array}$ & $\begin{array}{c}\mathrm{C}^{-M o-T_{x}} \\
\mathrm{Mo}^{+6}\end{array}$ & 38 \\
\hline $\begin{array}{c}\mathrm{Mo}_{1.33} \mathrm{CT}_{\mathrm{z}} \\
\text { (as-received) }\end{array}$ & $\begin{array}{l}228.5(231.7) \\
231.4(234.4)\end{array}$ & $\begin{array}{l}0.6(0.7) \\
1.7(2.0)\end{array}$ & $\begin{array}{l}0.83 \\
0.17\end{array}$ & $\begin{array}{c}\mathrm{C}-\mathrm{Mo}^{-} \mathrm{T}_{\mathrm{x}} \\
\mathrm{Mo}^{+6}\end{array}$ & 31 \\
\hline $\begin{array}{l}\mathrm{Mo}_{1.33} \mathrm{CT}_{\mathrm{z}} \\
\text { (3 cycles) }\end{array}$ & $\begin{array}{l}228.5(231.7) \\
231.5(234.5)\end{array}$ & $\begin{array}{l}0.6(0.7) \\
1.6(1.9)\end{array}$ & $\begin{array}{l}0.71 \\
0.29\end{array}$ & $\begin{array}{c}\mathrm{C}-\mathrm{Mo}^{-\mathrm{T}_{\mathrm{x}}} \\
\mathrm{Mo}^{+6}\end{array}$ & 31 \\
\hline $\begin{array}{c}\mathrm{Mo}_{1.33} \mathrm{CT}_{\mathrm{z}} \\
\text { (1000 cycles) }\end{array}$ & $\begin{array}{l}228.0(231.2) \\
231.0(234.0)\end{array}$ & $\begin{array}{l}0.7(0.8) \\
1.6(1.9)\end{array}$ & $\begin{array}{l}0.68 \\
0.32\end{array}$ & $\begin{array}{c}\mathrm{C}-\mathrm{Mo}^{-\mathrm{T}_{\mathrm{x}}} \\
\mathrm{Mo}^{+6}\end{array}$ & 31 \\
\hline
\end{tabular}


Stoichiometry and Surface Structure Dependence of HER Activity and Stability of Mox $\mathrm{CXenes}$

\section{Supporting Information}

a.

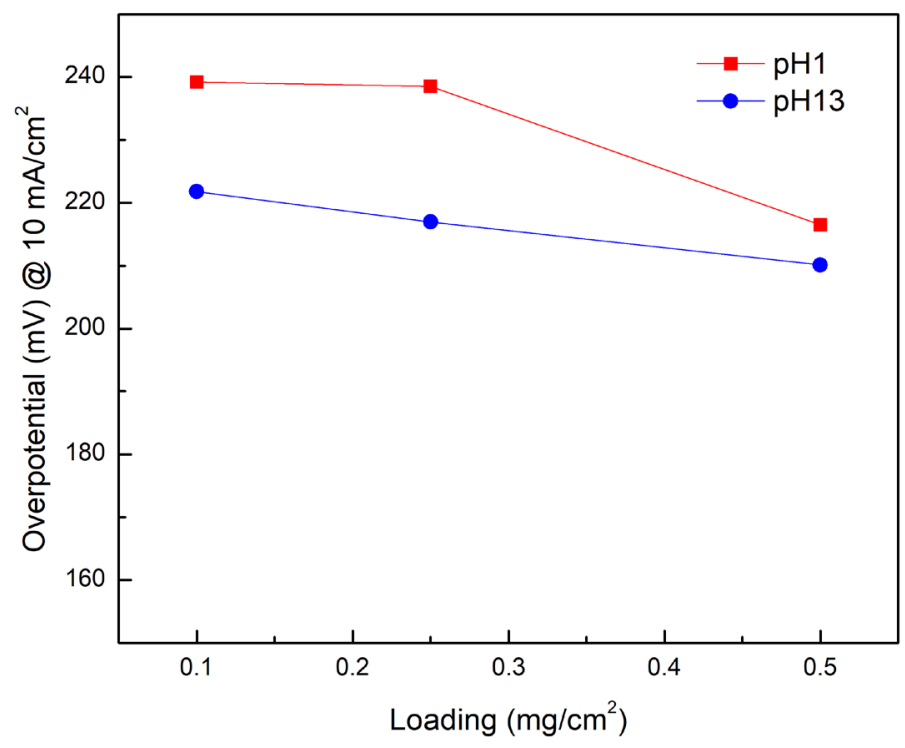

b.

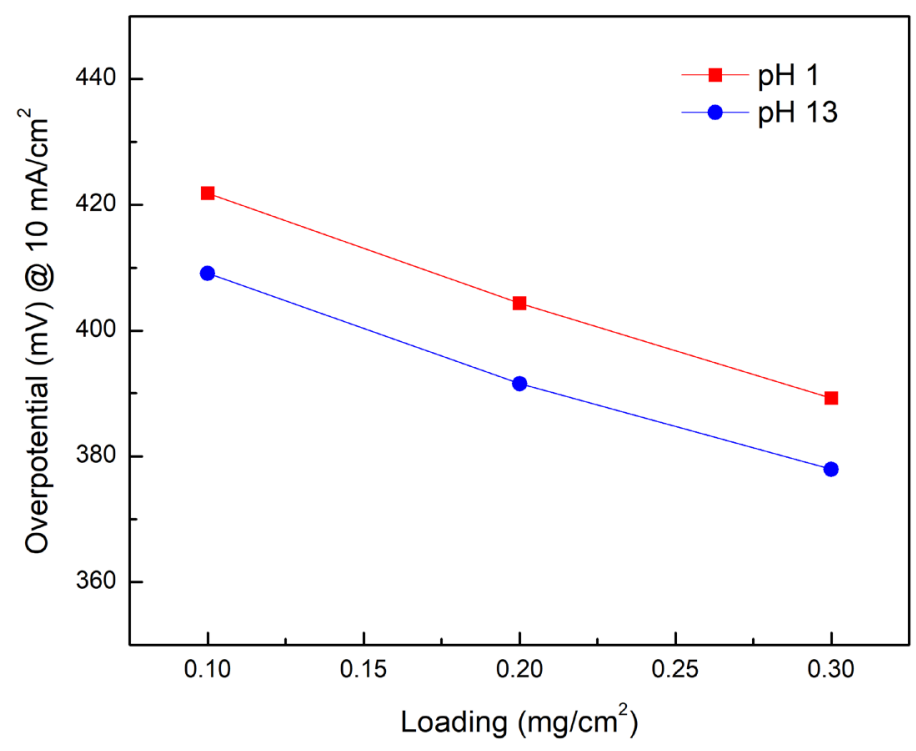

Figure S1: Overpotential at a current density of $10 \mathrm{~mA} / \mathrm{cm}^{2}$ as a function of loading in $0.1 \mathrm{M}$ $\mathrm{HClO}_{4}$ (red) and $0.1 \mathrm{M} \mathrm{KOH}$ (blue) for $\mathrm{Mo}_{2} \mathrm{C}(\mathrm{a})$ and $\mathrm{Mo}_{1.33} \mathrm{C}$ (b). 
a.

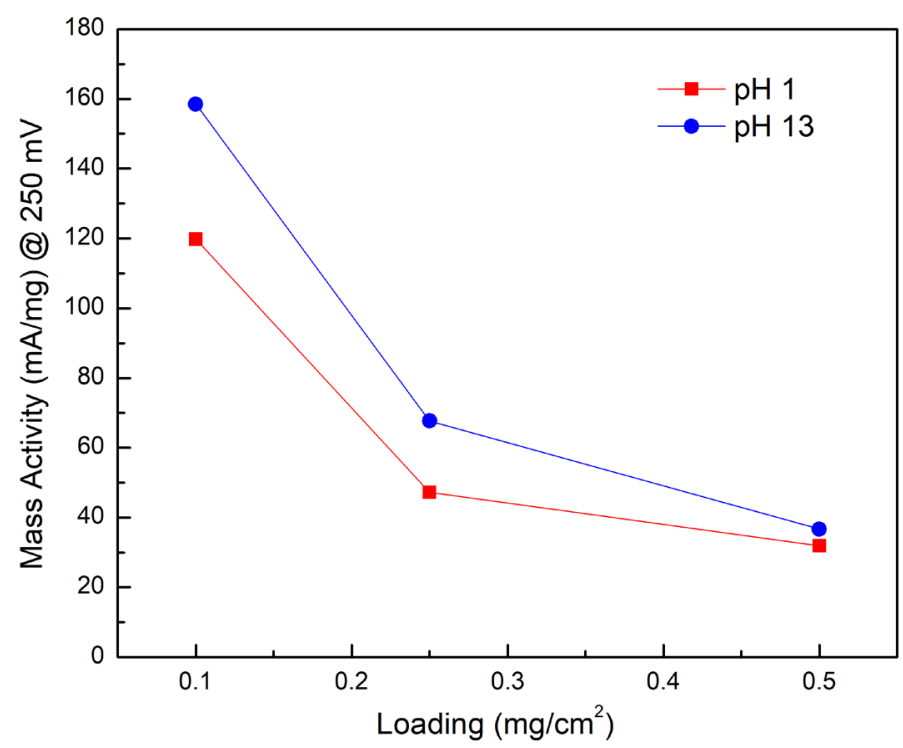

b.

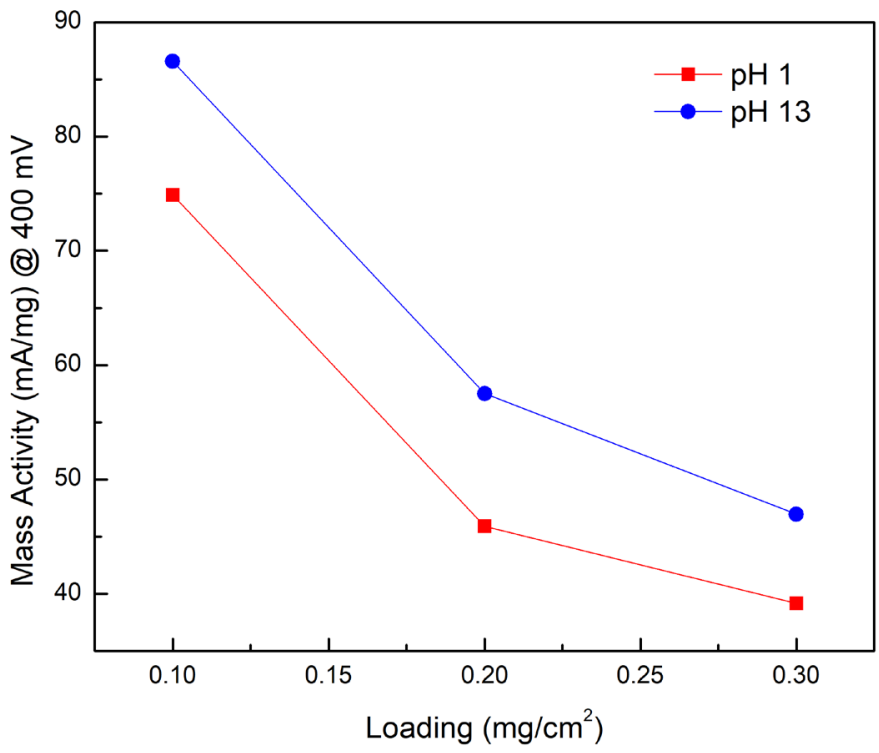

Figure S2: Mass activity, HER current normalized by catalyst mass, as a function of loading in $0.1 \mathrm{M} \mathrm{HClO}_{4}$ (red) and $0.1 \mathrm{M} \mathrm{KOH}$ (blue) for $\mathrm{Mo}_{2} \mathrm{C}$ at an overpotential of $250 \mathrm{mV}$ (a) and $\mathrm{Mo}_{1.33} \mathrm{C}$ at an overpotential of $400 \mathrm{mV}(\mathrm{b})$. 


\section{Roughness Factor Calculation}

Hydrogen evolution reaction (HER) currents on PGM free catalysts are usually normalized by a capacitively measured roughness factor ${ }^{1,2}$. Capacitance of $\mathrm{Mo}_{2} \mathrm{C}$ and $\mathrm{Mo}_{1.33} \mathrm{C}$ (mass loading: 0.1 $\mathrm{mg} / \mathrm{cm}^{2}$ ) was calculated from double layer charging by cycling potential between $0.05-0.4 \mathrm{~V}$ (vs RHE) at different scan rates $(50,100,150,200,250,300 \mathrm{mV} / \mathrm{s})$ as shown in Fig. S3a and Fig. S3b. The measured capacitive currents at $0.2 \mathrm{~V}$ (vs RHE) are plotted as a function of scan rate in Fig. $\mathrm{S} 3 \mathrm{c}$ and the slope of the linear fit gives the specific capacitance of $\mathrm{Mo}_{2} \mathrm{C}$ and $\mathrm{Mo}_{1.33} \mathrm{C}$. We observe a slightly higher specific capacitance for $\mathrm{Mo}_{1.33} \mathrm{C}\left(24.3 \mathrm{mF} / \mathrm{cm}^{2}\right)$ compared to the specific capacitance of $\mathrm{Mo}_{2} \mathrm{C}\left(15.3 \mathrm{mF} / \mathrm{cm}^{2}\right)$. Roughness factor (RF) is obtained by taking the ratio of the specific capacitance of MXenes to that of bare glassy carbon electrodes $\left(0.0153 \mathrm{mF} / \mathrm{cm}^{2}\right)$ giving values of 1000 and 1588 for $\mathrm{Mo}_{2} \mathrm{C}$ and $\mathrm{Mo}_{1.33} \mathrm{C}$ respectively. This indicates that $\mathrm{Mo}_{1.33} \mathrm{C}$ has a much larger active surface area compared to $\mathrm{Mo}_{2} \mathrm{C}$. 
a.

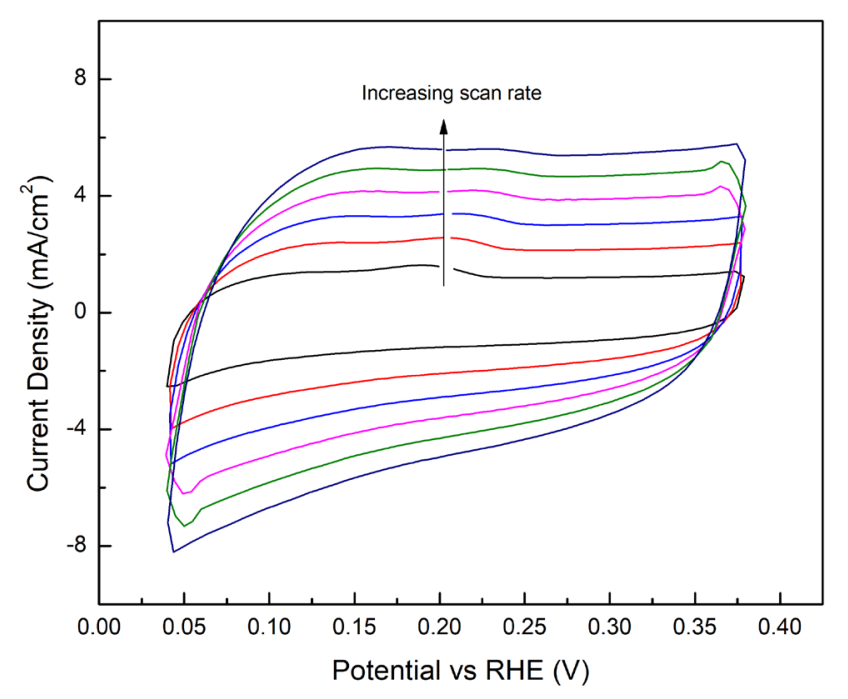

b.

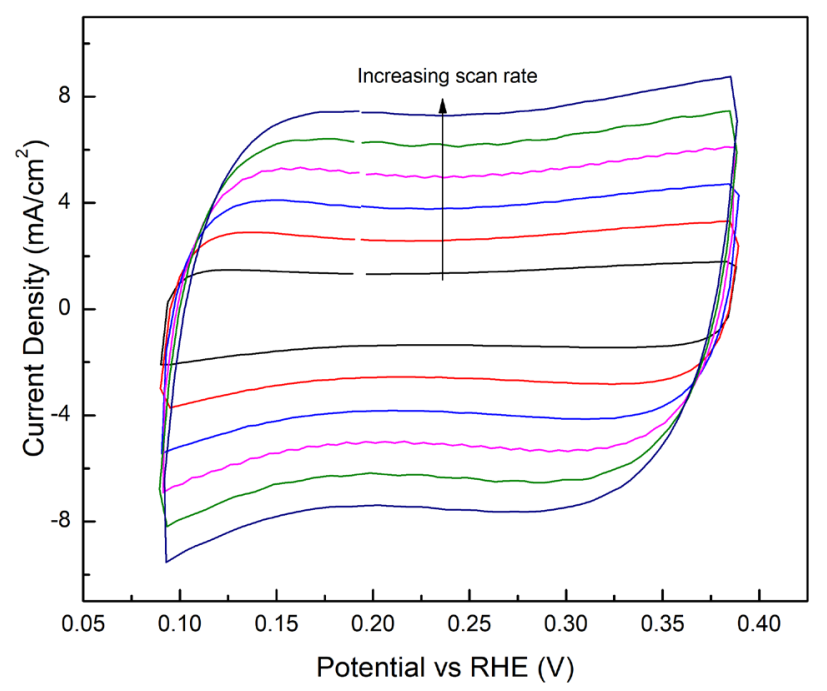

c.

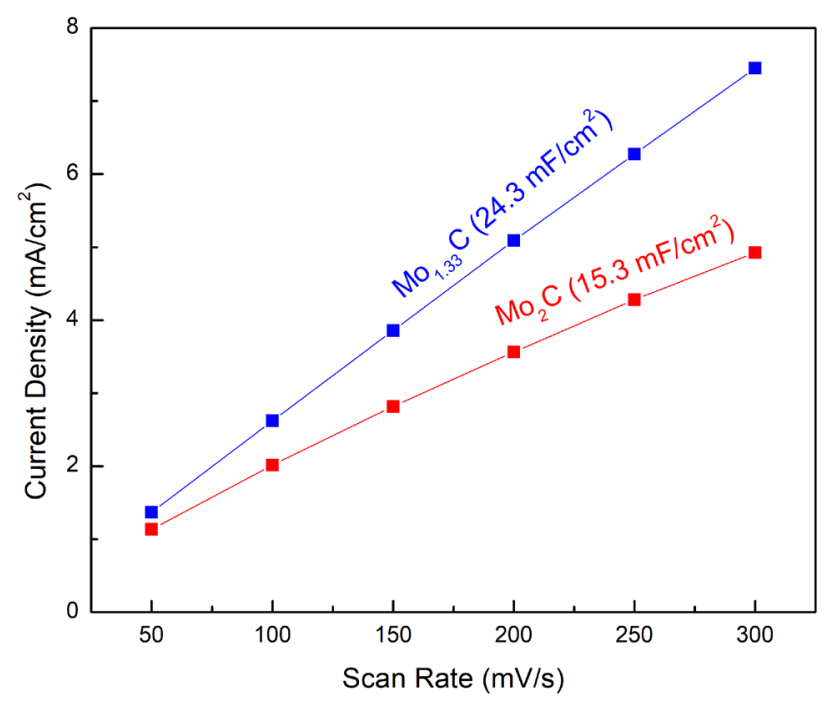

Figure S3: Electrochemical capacitance measurement in $0.1 \mathrm{M} \mathrm{HClO}_{4}$ at a loading of $0.1 \mathrm{mg} / \mathrm{cm}^{2}$ for $\mathrm{Mo}_{2} \mathrm{C}$ (a) and $\mathrm{Mo}_{1.33} \mathrm{C}$ (b). Measured capacitive currents vs. scan rate for $\mathrm{Mo}_{2} \mathrm{C}$ and $\mathrm{Mo}_{1.33} \mathrm{C}$ (c). Capacitance and roughness factor (RF) are calculated from the slope. 


\section{Turnover frequency (TOF)}

TOF has been calculated for $\mathrm{Mo}_{2} \mathrm{C}$ through the following formula:

$$
T O F_{\text {avg }}=\frac{\text { Number of hydrogen turnovers per geometric area }}{\text { Number of sites per geometric area }}
$$

Geometric current density gives the number of hydrogen turnovers and are obtained at $200 \mathrm{mV}$ overpotential. The number of sites per geometric area can be estimated from the mass loading and the DFT calculated surface coverage of Seh et al. taking all $\mathrm{O}$ atoms as the active sites ${ }^{3}$.

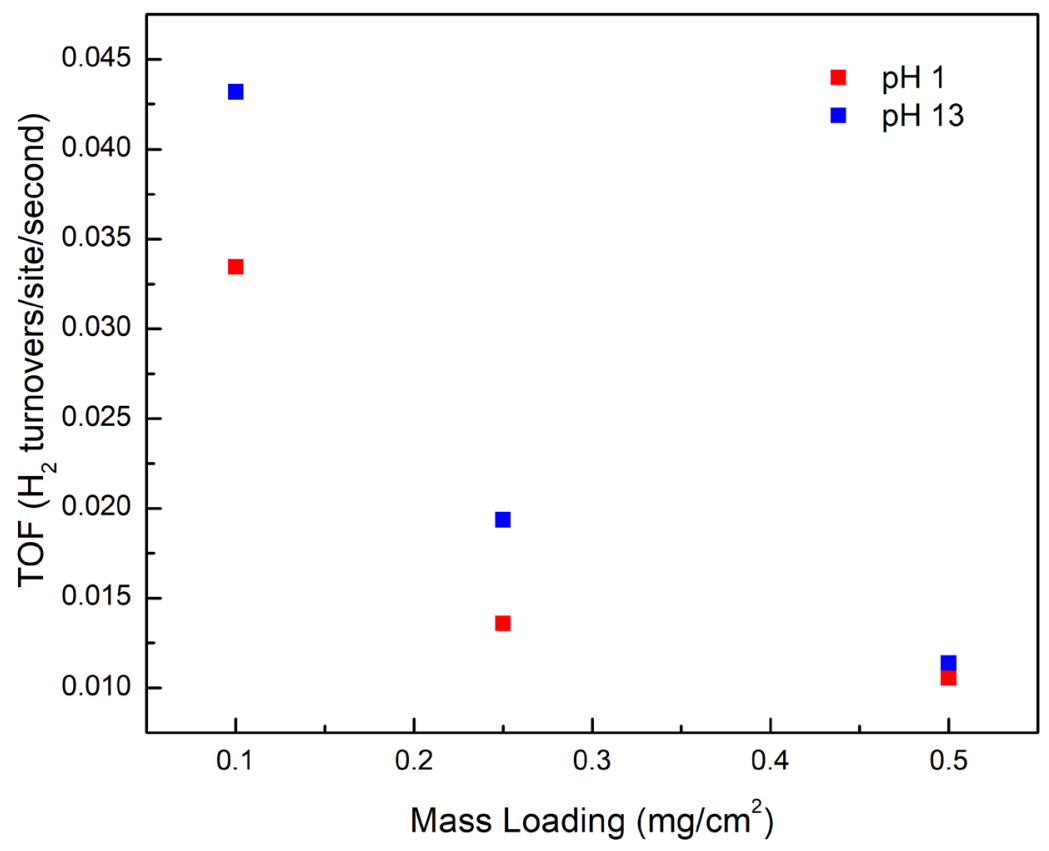

Figure S4: Turn Over Frequency (TOF) as a function of loading for $\mathrm{Mo}_{2} \mathrm{CT}_{\mathrm{x}}$ at an overpotential of $200 \mathrm{mV}$ in $0.1 \mathrm{M} \mathrm{HClO}_{4}$ (red) and $0.1 \mathrm{M} \mathrm{KOH}$ (blue). 


\section{References}

(1) Benck, J. D.; Chen, Z.; Kuritzky, L. Y.; Forman, A. J.; Jaramillo, T. F. 2012, 2-9.

(2) Li, Y.; Polakovic, T.; Curtis, J.; Shumlas, S. L.; Chatterjee, S.; Intikhab, S.; Chareev, D. A.; Volkova, O. S.; Vasiliev, A. N.; Karapetrov, G.; Snyder, J. 2018, 366, 50-60.

(3) Seh, Z. W.; Fredrickson, K. D.; Anasori, B.; Kibsgaard, J.; Strickler, A. L.; Lukatskaya, M. R.; Gogotsi, Y.; Jaramillo, T. F.; Vojvodic, A. ACS Energy Lett. 2016, 1, 589-594. 